Article

\title{
Applicability of Structure-from-Motion Photogrammetry on Forest Measurement in the Northern Ethiopian Highlands
}

\author{
Toru Sakai ${ }^{1, *}$, Emiru Birhane ${ }^{2}{ }^{(1)}$, Buruh Abebe ${ }^{2}$ and Destaalem Gebremeskel ${ }^{2}$ \\ 1 Japan International Research Center for Agricultural Sciences, Ibaraki 3058686, Japan \\ 2 Department of Land Resource Management and Environmental Protection, College of Dryland Agriculture \\ and Natural Resources, Mekelle University, Mekelle 231, Ethiopia; emiru.birhane@mu.edu.et (E.B.); \\ buruha111@yahoo.com (B.A.); destaalem14@gmail.com (D.G.) \\ * Correspondence: torus@affrc.go.jp; Tel.: +81-29-838-6628
}

Citation: Sakai, T.; Birhane, E.; Abebe, B.; Gebremeskel, D.

Applicability of Structure-from-

Motion Photogrammetry on Forest Measurement in the Northern Ethiopian Highlands. Sustainability 2021, 13, 5282. https://doi.org/ $10.3390 /$ su13095282

Academic Editor: Pablo Peri

Received: 2 April 2021

Accepted: 7 May 2021

Published: 9 May 2021

Publisher's Note: MDPI stays neutral with regard to jurisdictional claims in published maps and institutional affiliations.

Copyright: (C) 2021 by the authors. Licensee MDPI, Basel, Switzerland. This article is an open access article distributed under the terms and conditions of the Creative Commons Attribution (CC BY) license (https:/ / creativecommons.org/licenses/by/ $4.0 /)$.

\begin{abstract}
Ethiopia is one of the countries with the most degraded forest resources. Information on tree structure is needed at some points in the process to assess the appropriateness of forest management. The objectives are to examine whether the Structure from Motion (SfM)-based photogrammetry can be used to derive the forest structural parameters, and how the tree structural parameters can vary by location. In this study, the possible applicability of low-cost SfM-based photogrammetry was evaluated for forest management and conservation purposes in the Adi Zaboy watershed of the Northern Ethiopian highlands. In the watershed, dwarf Acacia etbaica was sparsely distributed. Consequently, the full three-dimensional point clouds of the individual trees were generated, which provided a wide variety of tree structural parameters in a non-destructive manner. The $R^{2}$ values for tree height, canopy width, and stump diameter were $0.936,0.891$, and 0.808 , respectively, and the corresponding RMSE values were $0.128 \mathrm{~m}, 0.331 \mathrm{~m}$, and $0.886 \mathrm{~cm}$. In addition, differences in forest structure and composition were caused by differences in the environment. The SfM-based photogrammetry would provide fundamental information to meet the demand of sustainable forest management from a morphological point of view, especially in forests of Ethiopian highlands.
\end{abstract}

Keywords: Acacia; forest management; highlands; photogrammetry; remote sensing; Structure from Motion (SfM)

\section{Introduction}

Forest resources provide a number of ecosystem services that contribute to the construction of resilient social ecosystems. Ethiopia, once blessed with abundant resources, is one of the most environmentally degraded countries in the Sahel belt [1]. Forest degradation is closely linked to population growth. The high population growth has dramatically increased deforestation, agricultural land expansion, and overgrazing by livestock, especially in the Ethiopian highlands [2-4]. Forest degradation over the most recent three decades covers around $23 \%$ of the land area [5]. The extensive forest degradation has also resulted in the extinction of various biota and a significant loss of biodiversity. In addition, the accelerated soil erosion on landscapes without vegetation washed away fertile topsoil, resulting in shallow soil with poor water storage capacity [1,6]. Almost 75\% of the most serious soil erosion occurs in the Ethiopian highland $[7,8]$. Forest degradation in Ethiopia is caused in the form of soil degradation, water resource degradation, and biodiversity loss [9]. The Tigray region of northern Ethiopia is one of the regions severely affected by forest degradation $[10,11]$. Once the forest is degraded, the natural regeneration of the forest resources is difficult. Sustainable forest management is a national priority in Ethiopia.

Information on the growth and survival of individual trees is needed at some points in the process to assess the appropriateness of management plans for the conservation and promotion of forest-related ecosystem services. Population size, density, and distribution reflect the process of regeneration and can reveal important insights into forest dynamics. 
Therefore, reliable measurements of the tree structure are important as a basis for decisionsupport in forest management [12,13]. However, a number of studies in forestry suggest that natural factors, as well as anthropogenic factors, can change the forest structure along the landscape, depending on size, shape, soil type, soil seed bank, topography, sun orientation, surrounding vegetation height, and species composition [14]. The environmental conditions in the Ethiopian highlands, where drought and poor soil are typical, are harsh for plant growth. The vegetations are characterized by dwarf trees and shrubs of mainly Acacia species. The tree structure found in the Ethiopian highlands is poorly understood.

Tree structural parameters, such as tree height, canopy volume, and trunk diameter, are important when trying to accurately and quantitatively evaluate the forest resources. However, traditional measurements of tree structural parameters have heavy workloads, low speeds, and enormous human and material resource requirements. Remote sensing, which can collect spatial information about objects at very high speeds without physical contact, is one of the most adopted techniques in the forestry sector [15-17]. Light detection and ranging (LiDAR) have proven to be a viable technology for producing the three-dimensional structure of a tree [18-21]. Utilizing air-borne and terrestrial LiDAR data, detailed monitoring of plant growth is possible at the organ level with high accuracy, but the major limitation of LiDAR is huge investment costs in advance. In recent years, photogrammetric approaches, such as $\mathrm{SfM}$, have been developed due to increased computing power and the widespread use of digital cameras. Cameras are cheaper than the LiDAR sensors. Miniaturized cameras onboard unmanned aerial vehicles (UAVs) are a compromise between size, weight, specifications, and cost. UAV has become a popular tool to generate three-dimensional forest information, i.e., photogrammetric point cloud, over large areas of forests due to the flexibility in data acquisition [22,23]. However, currently, there are no universal rules regarding the use of UAVs. UAVs can be used with permission from the local government in most countries, while some countries have very strict laws and regulations against UAV use. It is impossible to fly an UAV over some regions without flight permissions. To reconstruct the full three-dimensional shape of small vegetation with a sparse canopy, a number of studies have used a consumer-grade camera mounted on a monopod, and images have been taken while moving around the objects $[24,25]$. Consequently, the extraction of forest structural parameters can be performed using platforms, such as aircraft, UAV, and monopod, depending on the desired goals under specific research environments.

In this study, the possible applicability of low-cost SfM-based photogrammetry is evaluated for forest management and conservation purposes in the Adi Zaboy watershed in the Northern Ethiopian highlands. The objectives are to examine whether the SfM-based photogrammetry can be used to derive the forest structural parameters at an individual tree level, and (ii) how the tree structural parameters can vary by location. First, individual tree structural parameters derived from field surveys and the SfM-based photogrammetric method are compared. We focus on measuring tree height, canopy width, and stump diameter through the creation of three-dimensional point clouds of the tree. Second, the tree structural parameters are compared between the mountain ridge and valley areas of the Adi Zaboy watershed with different environmental conditions. Understanding the spatial patterns of tree structures and the underlying factors behind them is essential for designing forest management strategies.

\section{Materials and Methods}

\subsection{Study Site}

Ethiopia has a wide elevation range, from $126 \mathrm{~m}$ below sea level to $4620 \mathrm{~m}$ above sea level (Figure 1). The Ethiopian Plateau forms a considerable part of the country, where altitudes are greater than $1500 \mathrm{~m}$. Vegetation types and distribution patterns are determined by the geology, topography (elevation, slope, and aspect), soil, and climate conditions. The high mountain regions are dry tropical forests that differ significantly 
from wet tropical forests in terms of their structure, diversity, species composition, leafing phenology, and other functional aspects.

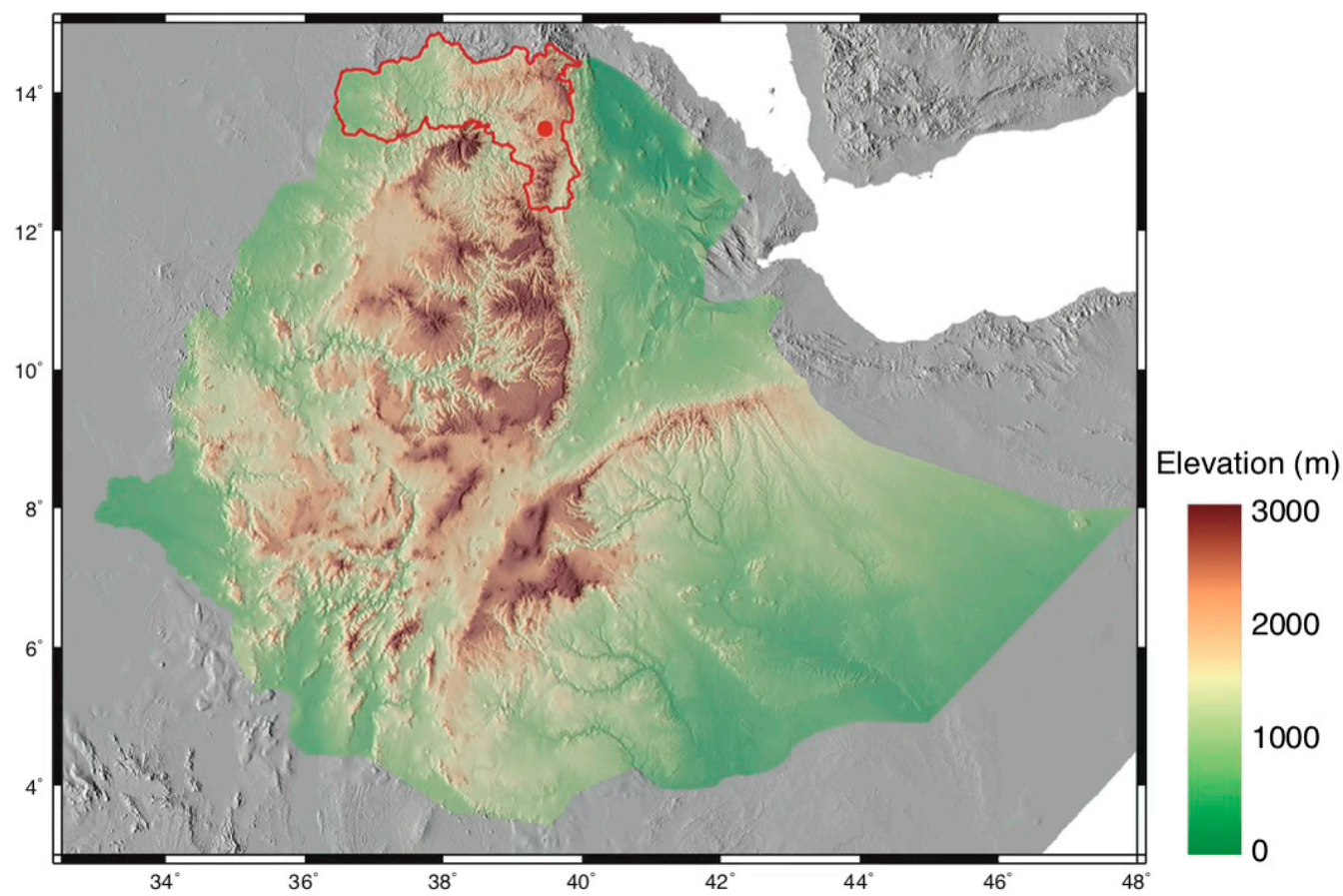

Figure 1. Study site in the Adi Zaboy watershed (red dot) in the Northern Ethiopia highlands. The red line shows the Tigray region.

This study was conducted in the Adi Zaboy watershed in northern Ethiopia (Figures 1 and 2). The watershed is located at $13.59^{\circ} \mathrm{N}$ and $39.02^{\circ} \mathrm{E}$ and covers a land area of 1382 ha. The elevation ranges from approximately 2050 to $2300 \mathrm{~m}$ a.s.l., with fairly flat to steeply sloping terrain. Annual precipitation fluctuates significantly during the year, from approximately $300 \mathrm{~mm}$ to $1000 \mathrm{~mm}$, with the majority of precipitation concentrated in a single rainy season between June and September. The air temperature is approximately $30{ }^{\circ} \mathrm{C}$, with minimal seasonal variation. Trees in the Adi Zaboy watershed are predominantly Acacia etbaica Schweinf. NOTE: In this study, the genera Vachellia and Acacia are mentioned interchangeably because some Acacia species have been categorized under the genus Vachellia from 2005 but are still classified under the genus Acacia in many studies.

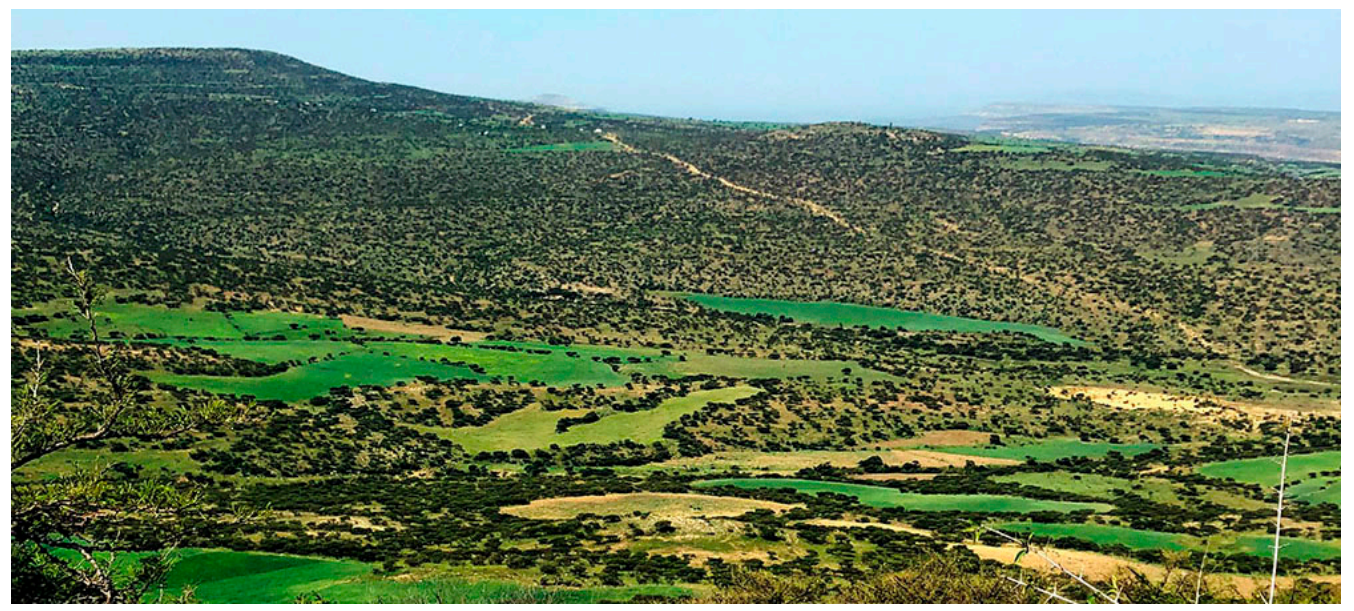

Figure 2. Landscape of the Adi Zaboy watershed. 


\subsection{Field Measurements}

Field measurements were conducted in September 2018 at the end of the rainy season, when tree growth was most active, and leaves were abundant. A total of 10 plots $(20 \mathrm{~m} \times 20 \mathrm{~m})$ were established in the mountain valley (approximate elevation of $2050 \mathrm{~m}$ a.s.l.) and ridge (approximate elevation of $2290 \mathrm{~m}$ a.s.l.) areas of the Adi Zaboy watershed to compare the distribution, abundance, and structure of trees under different environmental conditions. High soil erosion and soil degradation occurred in the mountain ridge areas, whereas soil was deposited in the mountain valley areas by runoff. There is also a reservoir near the mountain valley areas, which creates different soil water conditions between the mountain valley and ridge areas. All plots were established on fairly flat terrain to reduce the influence of other topographic factors, such as slope and aspect.

In each plot, individual tree height, canopy width, and stump diameter at $0.3 \mathrm{~m}$ above ground level were measured by direct and indirect methods (Figure 3). Generally, the trunk diameter at breast height (DBH), i.e., $1.3 \mathrm{~m}$ above ground level, is used as the primary independent variable for estimating tree biomass rather than the stump diameter. However, it is difficult to measure the DBH of trees or shrubs less than $3 \mathrm{~m}$ in height because of the complex forking structure. Therefore, the use of stump diameter at $0.3 \mathrm{~m}$ above ground level is very common for forest management in the highlands of Ethiopia [26,27]. As a direct method of measuring tree structural parameters, the stump diameter of all sprouting stumps (i.e., a, b, and c in Figure 3) was individually measured to the nearest $1 \mathrm{~mm}$ using a steel tape for DBH measurement. Tree height was measured from the ground to the tree tip using a height-measuring rod. Canopy width was measured in two cross directions (east to west and north to south) using a surveyor's tape. The summary statistics of the inventory data, such as the mean, standard deviation (SD), maximum, and minimum values of the tree height, canopy width, basal area, are shown in Table 1. Furthermore, the SfM method was used as an indirect method of measuring tree structural parameters. Details of the SfM method are described in Section 2.3.
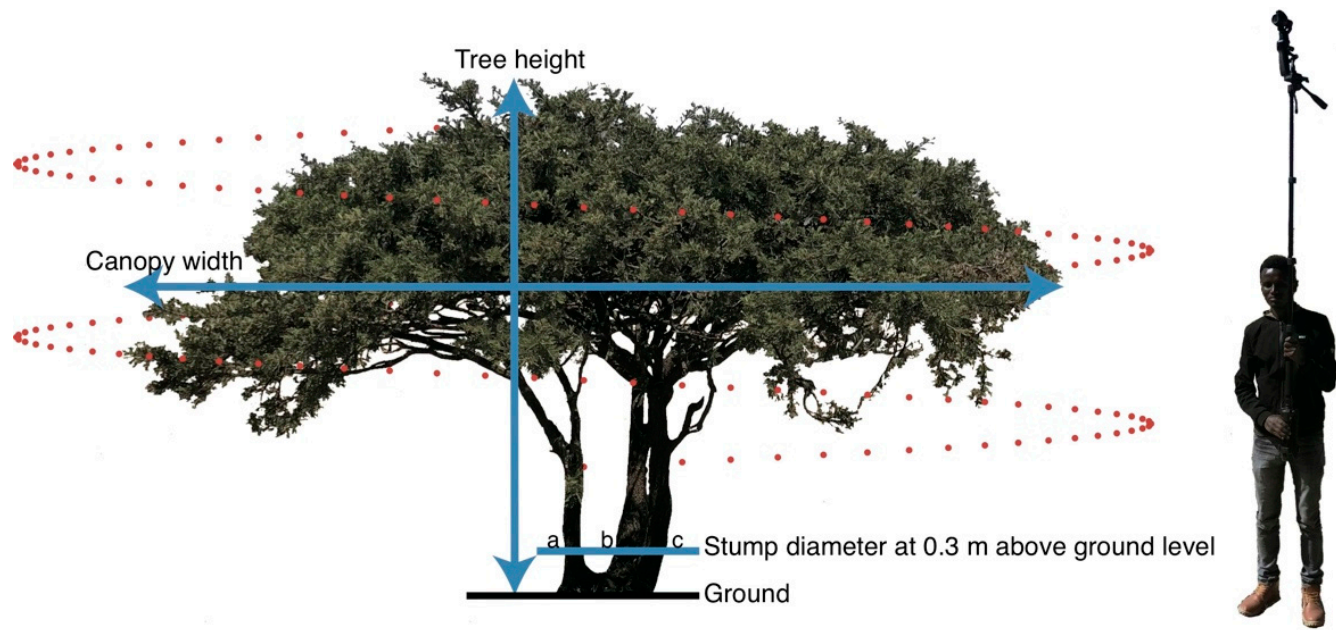

Figure 3. Field measurement of tree structural parameters. Blue lines show the tree height, canopy width, and stump diameter measured using a height-measuring rod and a surveyor's tape. The diameter of each stump (i.e., a, b, and c) was measured at $0.3 \mathrm{~m}$ above ground level. Red points show locations of images taken by the camera in a spiral shape for the Structure from the Motion method. 
Table 1. Summary statistics of the inventory data.

\begin{tabular}{|c|c|c|c|c|c|c|c|c|c|c|c|c|c|c|}
\hline \multicolumn{2}{|c|}{ Plot \# } & \multirow[t]{2}{*}{ Tree \# } & \multicolumn{4}{|c|}{ Tree Height (m) } & \multicolumn{4}{|c|}{ Mean Canopy Width (m) } & \multicolumn{4}{|c|}{ Basal Area $\left(\mathrm{cm}^{2}\right)$} \\
\hline & & & Mean & SD & Max & Min & Mean & SD & Max & Min & Mean & SD & $\operatorname{Max}$ & Min \\
\hline \multirow[t]{5}{*}{ Ridge } & 1 & 9 & 1.45 & 0.45 & 2.20 & 0.70 & 2.41 & 1.18 & 4.95 & 0.70 & 59.5 & 57.3 & 159.3 & 5.3 \\
\hline & 2 & 9 & 1.54 & 0.35 & 2.11 & 1.12 & 2.54 & 0.78 & 3.45 & 1.00 & 80.6 & 47.8 & 148.5 & 16.6 \\
\hline & 3 & 8 & 1.60 & 0.40 & 2.07 & 1.00 & 3.19 & 0.97 & 4.35 & 1.80 & 102.3 & 90.5 & 291.5 & 18.3 \\
\hline & 4 & 11 & 1.79 & 0.16 & 2.02 & 1.57 & 3.31 & 0.77 & 4.20 & 2.15 & 123.9 & 53.3 & 189.8 & 48.7 \\
\hline & 5 & 14 & 1.71 & 0.33 & 2.19 & 0.85 & 2.54 & 0.77 & 3.80 & 0.98 & 85.5 & 50.3 & 194.0 & 7.1 \\
\hline \multirow[t]{5}{*}{ Valley } & 6 & 11 & 1.64 & 0.52 & 2.61 & 0.83 & 2.25 & 0.73 & 3.35 & 1.00 & 60.6 & 42.3 & 129.6 & 6.2 \\
\hline & 7 & 9 & 2.11 & 1.03 & 3.28 & 0.81 & 2.73 & 1.64 & 5.10 & 1.15 & 109.4 & 105.4 & 252.8 & 5.3 \\
\hline & 8 & 13 & 2.14 & 0.71 & 3.24 & 0.74 & 2.95 & 1.01 & 4.55 & 1.60 & 125.8 & 87.4 & 273.2 & 8.0 \\
\hline & 9 & 14 & 1.82 & 0.35 & 2.56 & 1.23 & 2.80 & 0.62 & 4.05 & 1.75 & 92.4 & 43.1 & 181.5 & 39.3 \\
\hline & 10 & 12 & 1.53 & 0.29 & 1.93 & 1.01 & 2.57 & 0.77 & 3.70 & 1.35 & 64.4 & 51.6 & 144.3 & 10.6 \\
\hline
\end{tabular}

\subsection{Structure from Motion (SfM)}

Point clouds of individual trees were generated to obtain information on tree structure using the SfM method. First, image acquisition was done in the field. We placed four color panels of $30 \mathrm{~cm} \times 30 \mathrm{~cm}$ near the target tree and measured the center position of the panels with GPS, which represented the ground control points (GCPs) to georeference the point cloud. RGB images were taken around the target tree and color panels in vertical spirals from various angles using a camera (OSMO+, DJI, Shenzhen, China) attached to a monopod (Figure 3). The camera angle of OSMO+ was remotely controlled using a gimbal. The spiral path was 1-2 $\mathrm{m}$ from the outer edge of the tree canopy. For simplicity of operation, the images were recorded in video mode in MOV file format with $4096 \times 2160$ pixels at 24 fps. Data acquisition took approximately 1-3 min per tree.

Second, the image analysis was performed in the laboratory. Two still JPG format images per second were extracted from the MOV file to satisfy horizontal and vertical overlaps of more than $70 \%$. Further increases in the number of still images did not contribute to the accuracy but took more time to analyze. A dataset of 150-300 JPG images for each target tree was aligned with indirect pitch/roll/aspect calculations using Agisoft Metashape software. JPG images that could not be confidently aligned in vertical spirals were excluded from the analysis. Finally, a dense point cloud was generated from every dataset and re-projected to the UTM zone 37N WGS84 in units of meters. In this study, the dense point cloud was extracted in a quadrangular prism form that resembles the shape of the tree crown as much as possible with 40-50 million points and exported as a TXT file format for further processing.

\subsection{ANOVA}

Each plot exhibited a mixed distribution of small and large trees depending on the growth stage. In this study, we assigned trees into three categories: (1) seedlings (basal area $\left.<50 \mathrm{~cm}^{2}\right)$, (2) saplings $\left(50-100 \mathrm{~cm}^{2}\right)$, and (3) mature trees $\left(>100 \mathrm{~cm}^{2}\right)$ to determine differences in tree structure among categories. The basal area is the space covered by tree stumps at $0.3 \mathrm{~m}$ above ground level. Trees with multiple stumps were treated as a single individual.

The diversity of tree structures at different locations (i.e., valley and ridge areas in the watershed) was compared using a two-way analysis of variance (ANOVA). Tukey honestly significant difference (HSD) post-hoc tests were performed to separate means across different locations. All statistical analyses were performed using $R$ statistical software. 


\section{Results and Discussion}

\subsection{Three-Dimensional Tree Structure}

Figure 4 shows the point clouds of Acacia etbaica obtained using the SfM method. A comparison with photographs of the same trees reveals that the three-dimensional structure of the tree was well reconstructed. The generated point clouds were used to obtain tree structural parameters, including the tree height, canopy width, canopy depth, and stump diameter. However, some stumps were invisible because the leaves were distributed near the ground surface (for example, see Figure 4c). Therefore, we could not measure the stump diameter of all trees from the point clouds. Moreover, invisibility of the stump and ground surface is also related to tree height estimation. In this study, ground elevation was defined by the peak value that appeared at lower elevations in the histogram of point clouds in the $z$-axis (vertical direction); the point clouds for trees and ground were separated according to this threshold (Figure 5). As point clouds around tree canopy often include noise that appears as white, gray, and blue points from the sky, the tree height was derived as the distance from the ground elevation to quantiles corresponding to the 95th percentiles of tree point clouds to avoid noise.

Photographic measurements were performed for each individual tree (Figure 3); however, as dense clouds have positional information, they can be collected in plot units. Figure 6 shows the merged dense clouds in a $20 \mathrm{~m} \times 20 \mathrm{~m}$ plot. In ten plots, dwarfed trees with a maximum tree height of $3.3 \mathrm{~m}$ were sparsely distributed. When the monopod was extended, the camera protruded above the canopy (Figure 3). Therefore, it was possible to measure the structural parameters of trees using a camera mounted on a monopod in the field. Canopy width, canopy depth, and stump diameter were extracted using a ruler tool in Agisoft Metashape software. The accuracy was then evaluated through a comparison with the tree structural parameters obtained from field measurements.
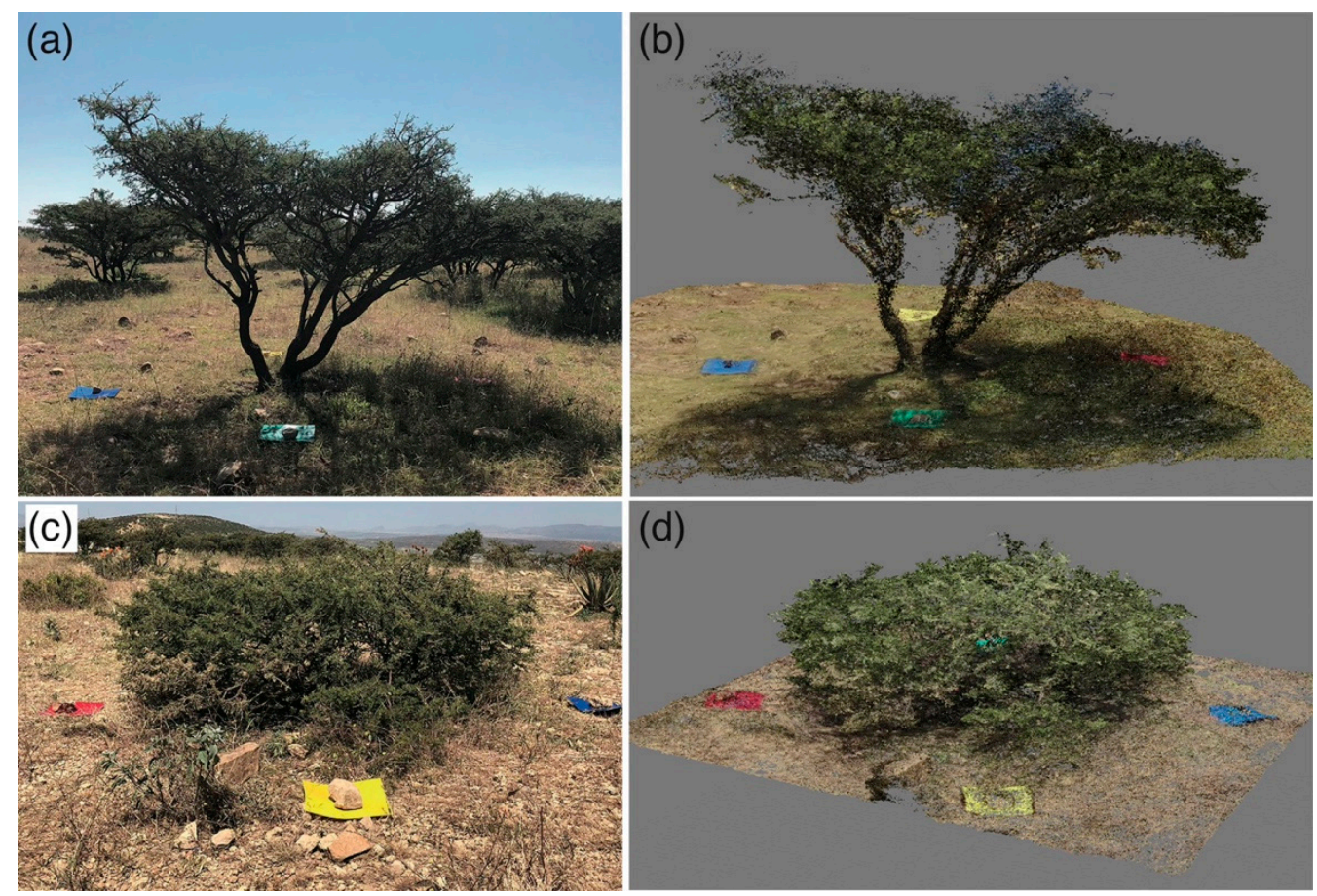

Figure 4. Comparisons of photographic (a,c) and point cloud (b,d) data of Acacia etbaica with umbrella-shaped $(\mathbf{a}, \mathbf{b})$ and hemispherical-shaped $(\mathbf{c}, \mathbf{d})$ canopies. 


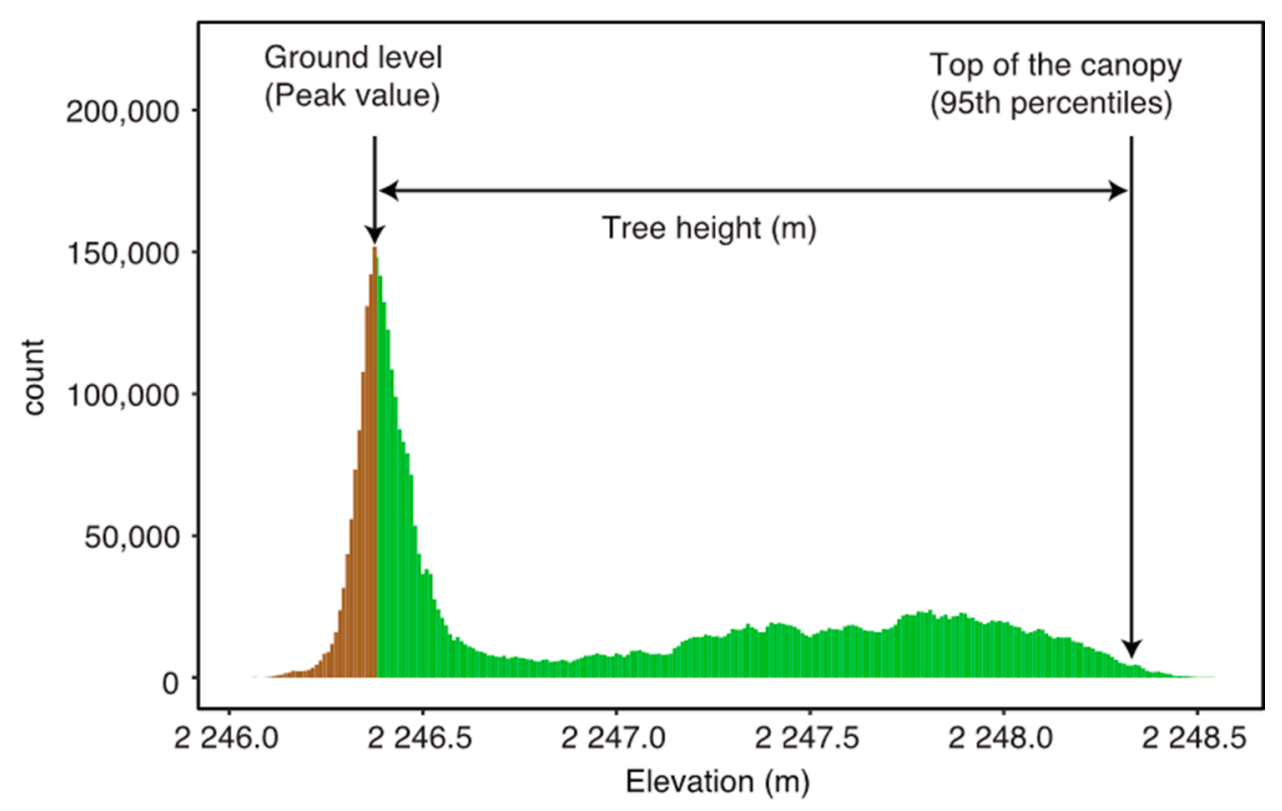

Figure 5. Example of tree height estimation from point clouds. The peak value on the $z$-axis of the histogram (elevation) was defined as the ground level, and the distance from the ground level to the 95th percentile of point cloud data for trees (green color) was defined as the tree height.

(a)

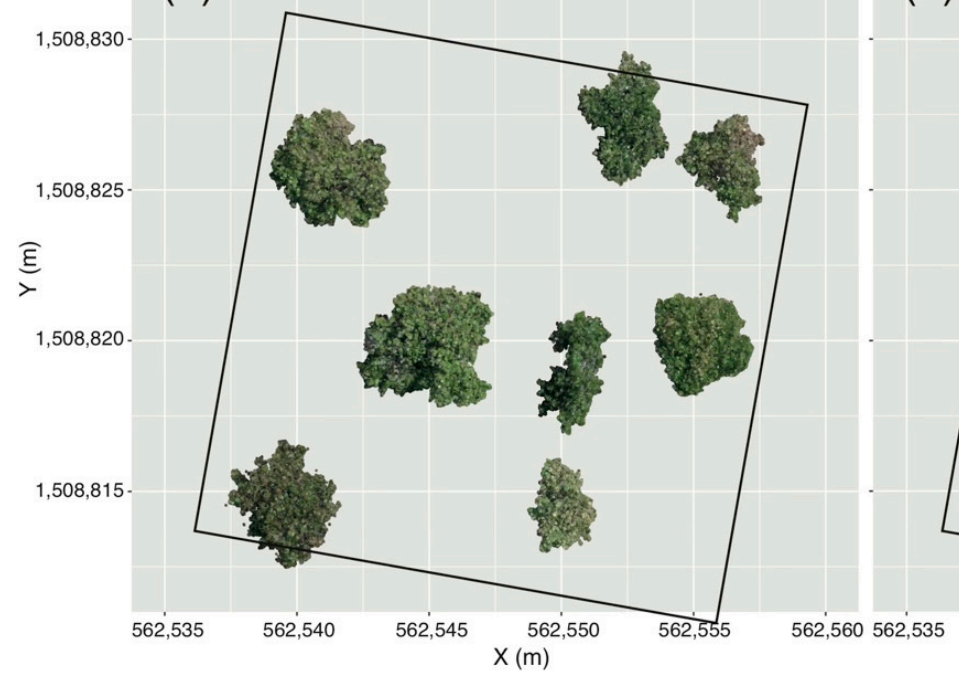

(b)

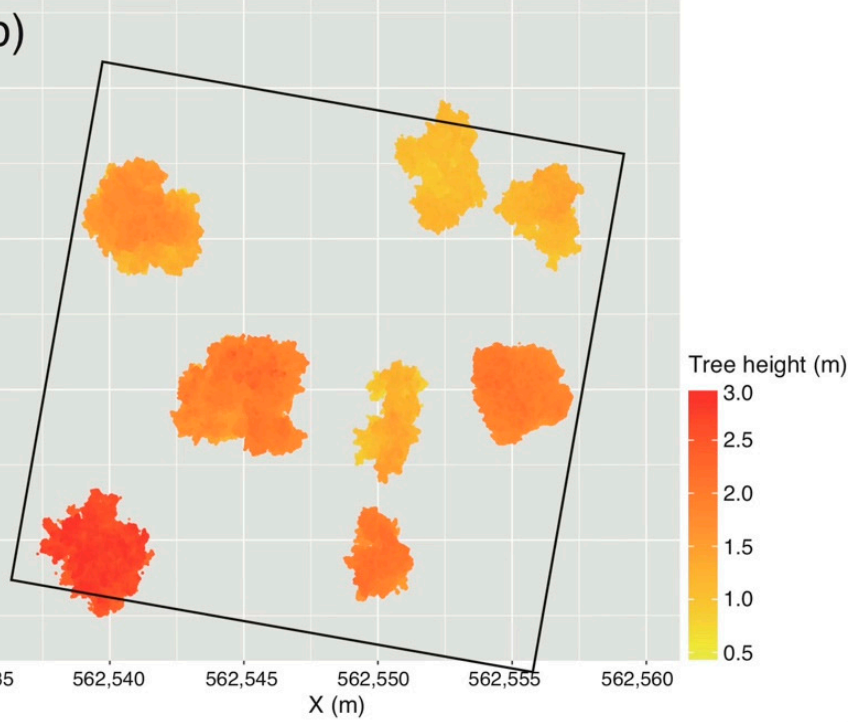

Figure 6. Examples of (a) point clouds and (b) tree height data of Acacia etbaica in one plot (20 $\mathrm{m} \times 20 \mathrm{~m})$ in a mountain ridge area in the Adi Zaboy watershed derived using the SfM method $(n=8)$. Point clouds were re-projected to UTM zone $37 \mathrm{~N}$ WGS84.

Figure 7 shows the relationships between field-based and SfM-based tree structural parameters, that is, (a) tree height, (b) canopy width, and (c) stump diameter. All relationships followed a 1:1 line, indicating that the SfM-based method is suitable for determining tree structural parameters. However, the coefficient of determination $\left(R^{2}\right)$ and root mean squared error (RMSE) varied slightly depending on the measurement parts of the tree. The $R^{2}$ values for tree height, canopy width, and stump diameter were 0.936, 0.891, and 0.808, respectively, and the corresponding RMSE values were $0.128 \mathrm{~m}, 0.331 \mathrm{~m}$, and $0.886 \mathrm{~cm}$. The $R^{2}$ value was highest for tree height because of noise removal from the point clouds. As the top of the canopy of Acacia etbaica was often flat and many point clouds gathered at the top of the canopy, it was relatively easy to remove promi- 
nent noise. However, despite noise removal, the RMSE value for tree height was rather high at $0.128 \mathrm{~m}$ (Figure 7a). This may be explained by the fact that measurement errors from height-measuring rods are also included in tree height measurements [28]. Persson et al. [29] demonstrated that a significant portion of the RMSE of tree height estimates conducted via LiDAR systems could be caused by errors in field-based measurements. Although based on a hypothesis that field-based measurements are more accurate and reliable, Sibona et al. [30] noted the importance of training and experience of operators in the quality of the field-based measurements. Generally, well-educated and experienced operators are acknowledged to provide more accurate data than beginners with only basic knowledge. On the other hand, the SfM method is available to all people with little training or expertise. However, tree height measurements using a camera mounted on a monopod are limited to low-height trees. Fortunately, Acacia etbaica is dwarfed in the highlands of Ethiopia and sparsely distributed. It would also be possible to apply the SfM method to larger trees by using an unmanned aerial vehicle (UAV) [31,32].
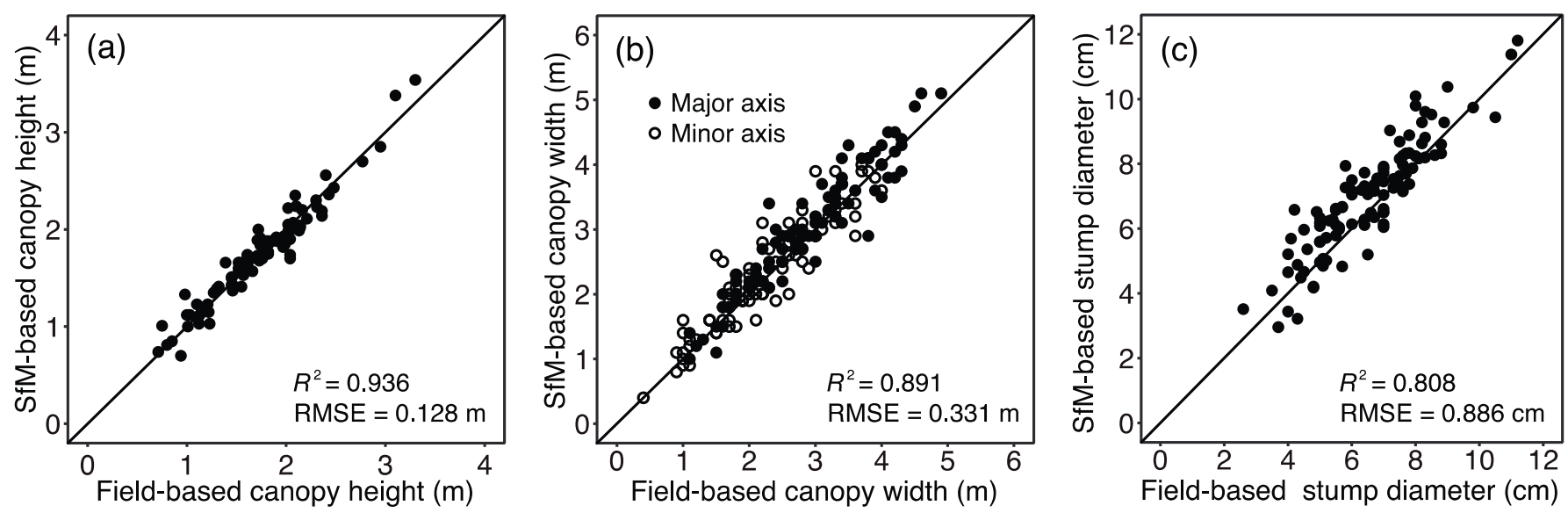

Figure 7. Relationships between field-based and SfM-based measurements for (a) tree height, (b) canopy width, and (c) stump diameter.

Similarly, a lower $R^{2}$ of 0.891 and a higher RMSE of $0.331 \mathrm{~m}$ were obtained for the canopy width measurements (Figure $7 \mathrm{~b}$ ). The canopy width was measured in two directions, north-south and east-west, because the shape of the canopy is often approximated by an ellipse. However, it was difficult to accurately measure the canopy width in two directions in the field, even on flat terrain; thus, there might be mismatches in the measurement points between field-based and SfM-based measurements. Therefore, the lower $R^{2}$ and higher RMSE values for canopy width measurements do not necessarily mean that the SfM method is not accurate. Rather, the canopy area based on the SfM method would be more accurate than that assuming an elliptical shape because of the distorted shape of the canopy (Figure 6). Although DBH has often been used to estimate biomass in forestry, the development of LiDAR observations has increased the opportunity to use the canopy area as an alternative parameter [33,34]. The canopy area is also an important parameter influencing carbon gain in relation to leaf photosynthesis, total leaf area, and leaf lifespan $[34,35]$. 
The stump diameter $R^{2}$ and RMSE values of 0.808 and $0.886 \mathrm{~cm}$, respectively, were the lowest among all tree structural parameters (Figure 7c). Note that the RMSE value of $0.886 \mathrm{~cm}$ was significantly lower. Previous studies using the SfM method also gained DBH estimates with similar RMSE values from $0.911 \mathrm{~cm}$ to $5.07 \mathrm{~cm}$ [36-40]. These RMSE ranges may represent the potential error of the SfM method because most dendrometers can provide adequate measurements of the outside bark diameter for field inventory applications [41]. However, the $R^{2}$ value for stump diameter estimation was the lowest (Figure 7), which is probably due to the ambient light conditions. A number of studies have noted that light conditions affect the contrast and shadow on the object [42]. Therefore, it is recommended to conduct photographic surveys under an overcast sky, because fewer shadows create a high-contrast background to capture thin branches [36]. In this study, we conducted the photographic survey in uneven light environments; therefore, it was difficult to obtain complete point coverage for some stumps. Light and shadow effects greatly affected the quality of the point clouds and, consequently, the performance of the SfM method. Reconstructing stumps depends on the visibility in multiple images, as well as the level of detail and sharpness of the images [43].

Despite these errors, SfM photogrammetry was highly effective for phenotyping trees in forests with sparsely distributed dwarf trees, such as the highlands of Ethiopia. Data acquisition is very simple, using only a camera and a monopod (Figure 3), rapid, with a data acquisition time for each individual tree of only $1-3 \mathrm{~min}$, and requires no expert knowledge. For practical forestry applications, instruments need to be inexpensive, precise, and easy to use. Some efficient instruments, such as LiDAR and UAV, are often too expensive, complex, and difficult to carry in the field or to obtain permission for use, depending on the country and region. Thus, reasonably accurate instruments are attractive for field surveys. Although we used commercial software (Metashape, Agisoft) for the generation of point clouds, open-source software is available as an effective alternative. However, this SfM method may be challenging in dense forests with high tree heights and rough terrain, where the equipment may be difficult to move.

\subsection{Characteristics of Tree Structure}

A significant portion of the Adi Zaboy watershed is exposed to cultivation and grazing (Figure 2), although these actions are currently partially prohibited by exclosures [44]. Agricultural expansion has reduced the forest area and overgrazing by large numbers of livestock has destroyed tree seedlings. Thus, human-induced disturbances are evident in the Adi Zaboy watershed. As a result, forests dominated by Acacia etbaica are sparsely distributed throughout the landscape. Monitoring forest structure and composition is important for appropriate forest management and conservation. The measurement of individual tree structural parameters is a foundation for understanding forest growth dynamics. In this study, five plots of $20 \mathrm{~m} \times 20 \mathrm{~m}$ were installed in mountain valley and ridge areas in the Adi Zaboy watershed to investigate changes in tree structures. In the Tigray region (Figure 1), Acacia species were introduced in the 1980s for the purpose of environmental rehabilitation and soil and water conservation [26]; hence, tree structure parameters are expected to be similar in these areas [45]. Possible variations can be attributed to site quality and environmental conditions.

As the tree structure of individual trees of Acacia etbaica was clearly different depending on the growth stage, the basal area was used as threshold values to divide trees into three growth stages, that is, seedlings, saplings, and mature trees (Figure 8), because the basal area provides a better measure of the relative importance of species composition $[46,47]$. Then, the tree structural parameters of the three growth stages were compared at different locations (Figure 9). The total number of Acacia etbaica trees per five plots in valley and ridge areas was 59 and 51, respectively. There were slightly more seedlings and saplings in valley areas than ridge areas. This suggests that the micro-environmental conditions of the valley might be more suitable for tree establishment, growth, and survival. However, there were no statistical differences in tree structural parameters between loca- 
tions, except for tree height (Figure 9). The tree height of mature trees in ridge areas was lower than that in valley areas (Figure 9d). Tree height might be related to the terrain position and exposure to the wind, and thus wind-exposed ridge trees were lower than valleys. It is well known that lower tree height ensures mechanical stability and reduces the potential for extreme wind damage. Acacia species typically have an umbrella-shaped canopy (Figure 4a); however, hemispherical-shaped canopies with a low tree height often appeared in ridge areas (Figure 4c). Variations in tree shapes might be caused by adaptation to local environments. Trees with hemispherical-shaped canopy inhibit diversity loss because of a reduction in heat and water loss by achieving the lowest surface-to-volume ratio [48]. These features are frequently found in vegetation that inhabits ecosystems with harsh physical conditions. The detection of Acacia with a hemispherical-shaped canopy may serve as a milestone, indicating unfavorable environmental conditions for plant growth. The presence of Acacia with a hemispherical-shaped canopy does not pose an absolute barrier to forest management activities; however, successful forest management should be assessed by sufficient numbers of seedlings, saplings, and mature trees as well as their growth rate for succession [49]. Our study provides useful morphological insights for developing management plans to support the effective conservation of plant species in the semi-arid highland climate of the Ethiopian highlands.
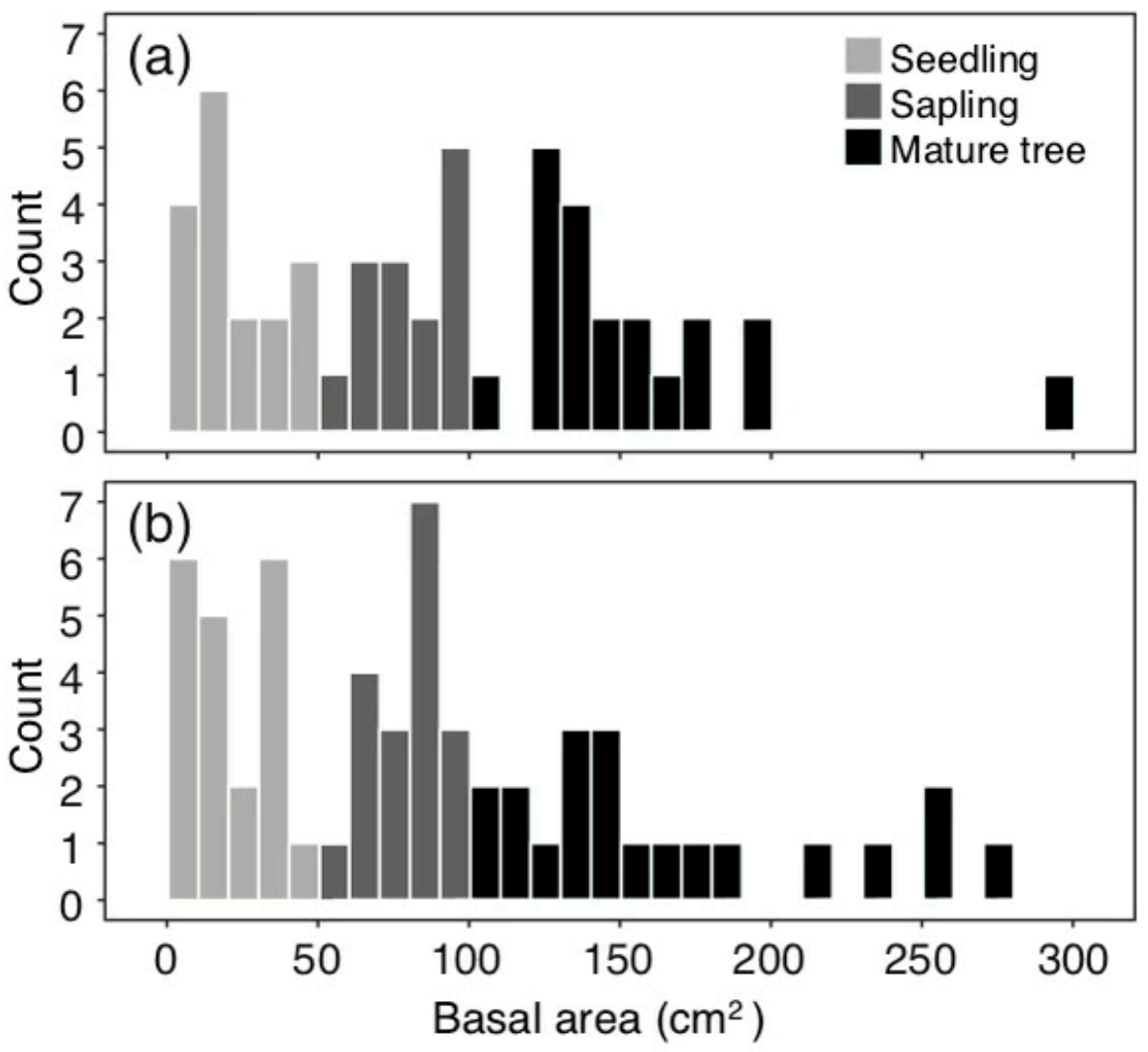

Figure 8. Histogram showing the basal area of Acacia etbaica in five plots for (a) mountain ridge areas and (b) valley areas in the Adi Zaboy watershed. Acacia etbaica are divided into three growth stages according to the BA, i.e., seedlings (basal area $<50 \mathrm{~cm}^{2}$ ), saplings $\left(50-100 \mathrm{~cm}^{2}\right.$ ), and mature trees $\left(>100 \mathrm{~cm}^{2}\right)$. 

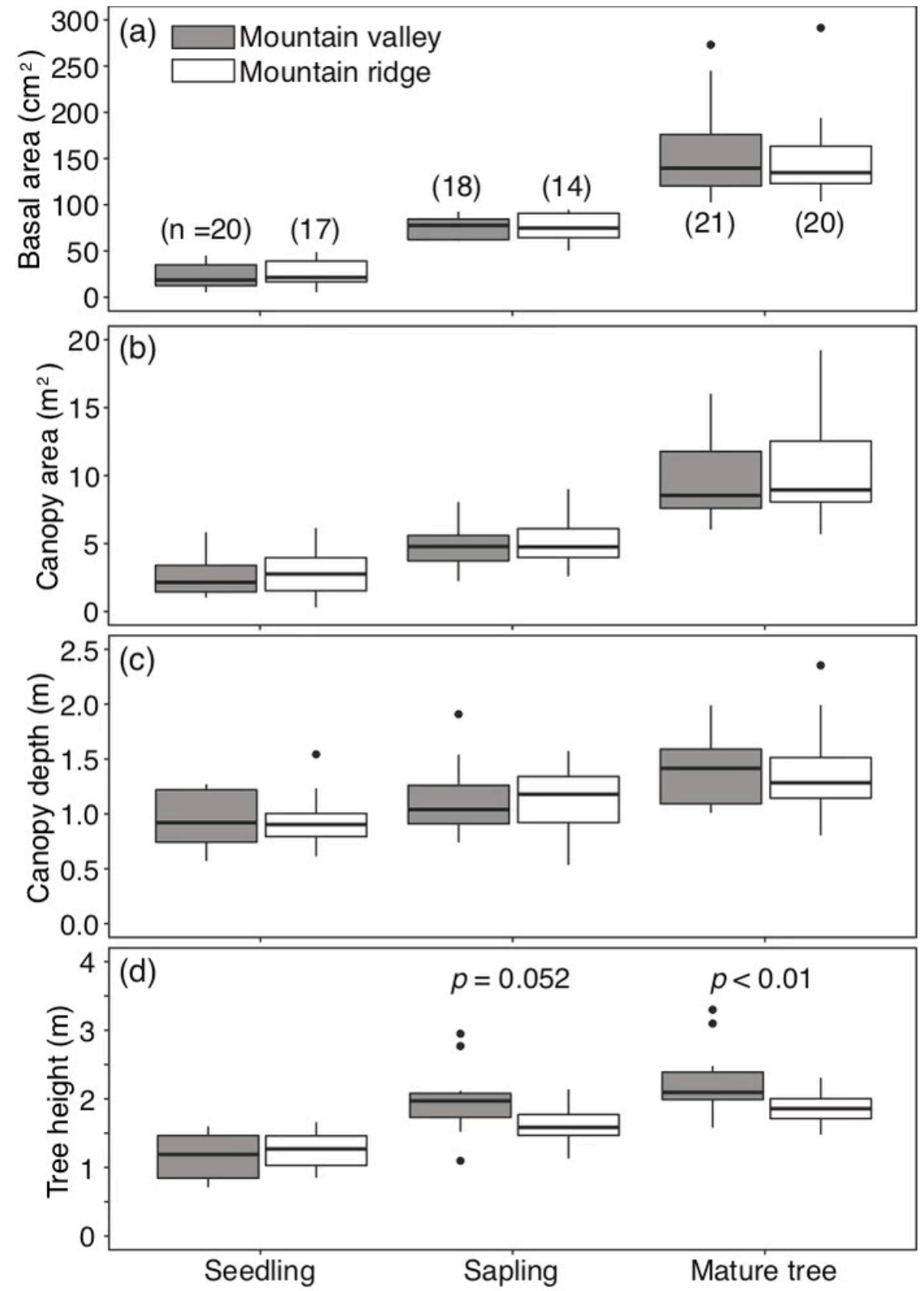

Figure 9. Boxplots of (a) basal area, (b) canopy area, (c) canopy depth, and (d) tree height for individual Acacia etbaica of three growth stages, i.e., seedlings, saplings, and mature trees, in mountain valley and ridge areas of the Adi Zaboy watershed. The numbers in parentheses represent the number of trees per five plots.

\subsection{Forest Management in the Highlands}

Assessment of tree biomass and carbon stock is important for the sustainability of forest management. Tree biomass can be estimated from the size of the tree in a nondestructive manner [50]. The empirical allometric model has been developed by assuming the power law relationship between tree diameter and biomass. However, trees seem to be able to sense environmental stresses and adaptively vary horizontal and vertical structures (Figure 4). Even among the same species, the tree structure varied by micro-environment and growth stage (Figure 9). Therefore, the non-consideration of diverse tree structures leads to large errors in biomass estimation. Our results support the need to develop site-specific allometric models by including additional information, such as tree height 
and canopy width $[26,27]$. The SfM method was able to effectively reconstruct the full three-dimensional tree structure (Figure 4). The complete tree structure description would be substantially improved to quantify biomass with a high level of accuracy. Additionally, periodic monitoring by the SfM method would provide a better understanding of the diverse growth strategies of trees that grow in harsh environments, which is an essential component of achieving sound forest measurement.

Moreover, the point clouds have location information by GPS (Figure 6), and thus it is possible to link tree structural parameters with a tree position on the ground. It would be useful for understanding how tree structures vary geographically, with terrain ranging from mountain ridges to valleys. However, we have to note that it takes time to acquire the data of individual tree structures by walking. Therefore, our results may not be enough to show the differences in tree structures by location. Further research needs to draw conclusions on this aspect. Monitoring from UAV or aircraft platforms is desirable on the watershed scale. A high-density point cloud is also acquired from these platforms [31,32]. An integrated approach that combines ground inventory work with GIS and remote sensing technologies can be an important tool for mapping tree resources leading to efficient and sustainable management.

\section{Conclusions}

In this study, the possible applicability of low-cost SfM-based photogrammetry was evaluated for forest management and conservation purposes in the Northern Ethiopian highlands. In the Adi Zaboy watershed, most of the trees were dominated by dwarf Acacia etbaica. The maximum tree height of Acacia etbaica was $3.3 \mathrm{~m}$. Therefore, the camera protruded above the canopy when the monopod was extended. Moreover, the sparse tree density allowed us to take pictures around the target tree in vertical spirals from various angles. As a result, the SfM-based photogrammetry generated the full three-dimensional point clouds of the individual trees, which provided a wide variety of tree structural parameters, such as tree height, canopy diameter, and stump diameter. The $R^{2}$ values for tree height, canopy width, and stump diameter were $0.936,0.891$, and 0.808 , respectively, and the corresponding RMSE values were $0.128 \mathrm{~m}, 0.331 \mathrm{~m}$, and $0.886 \mathrm{~cm}$. This study confirms the applicability of the SfM-based photogrammetry for three-dimensional tree structure measurements. The use of a low-cost consumer camera mounted on a monopod would be useful as alternatives to LiDAR and UAV.

In addition, we investigated how the tree structural parameters can vary by location. Population size, density, and distribution were compared in the mountain ridge and valley areas of the Adi Zaboy watershed. There were slightly more seedlings and saplings in valley areas than ridge areas. Moreover, in mountain ridge areas, trees with hemisphericalshaped canopy emerged, resulting in lower tree height of mature trees. Differences in forest structure and composition might be caused by differences in the environment. The microenvironmental conditions of the valley areas were more suitable for tree establishment, growth, and survival. Forest recovery depends on both natural and human factors. For a successful regeneration, sufficient amounts of seedlings and appropriate climate conditions are indispensable for establishment. The SfM-based photogrammetry would provide fundamental information to meet the demand of sustainable forest management from a morphological point of view, especially in forests of Ethiopian highlands.

Author Contributions: Conceptualization, T.S. and E.B.; methodology, T.S.; software, T.S.; validation, T.S.; formal analysis, T.S.; investigation, T.S., B.A., and D.G.; resources, T.S.; data curation, T.S., B.A., and D.G.; writing-original draft preparation, T.S.; writing—review and editing, E.B.; visualization, T.S.; supervision, T.S. and E.B.; project administration, T.S. and E.B.; funding acquisition, T.S. All authors have read and agreed to the published version of the manuscript.

Funding: This study was conducted as part of a research project sponsored by the Japan International Research Center for Agricultural Sciences (JIRCAS) on forest and farmland conservation for watershed management in the Ethiopian highlands. 
Acknowledgments: We thank all collaborators of JIRCAS and Mekelle University for participating in this research project.

Conflicts of Interest: The authors declare no conflict of interest.

\section{References}

1. Bishaw, B. Deforestation and land degredation in the Ethiopian highlands: A strategy for physical recovery. Northeast Afr. Stud. 2001, 8, 7-25. [CrossRef]

2. Lemenih, M.; Karltun, E.; Olsson, M. Soil organic matter dynamics after deforestation along a farm field chronosequence in southern highlands of Ethiopia. Agric. Ecosyst. Environ. 2005, 109, 9-19. [CrossRef]

3. Kindu, M.; Schneider, T.; Teketay, D.; Knoke, T. Drivers of land use/land cover changes in Munessa-Shashemene landscape of the south-central highlands of Ethiopia. Environ. Monit. Assess. 2015, 187. [CrossRef] [PubMed]

4. Solomon, N.; Hishe, H.; Annang, T.; Pabi, O.; Asante, I.K.; Birhane, E. Forest cover change, key drivers and community perception in Wujig Mahgo Waren forest of northern Ethiopia. Land 2018, 7, 32. [CrossRef]

5. Gebreselassie, S.; Kirui, O.K.; Mirzabaev, A. Economics of land degradation and improvement in Ethiopia. In Economics of Land Degradation and Improvement—A Global Assessment for Sustainable Development; Nkonya, E., Mirzabaev, A., von Braun, J., Eds.; Springer International Publishing: Cham, Switzerland, 2016; pp. 401-430. ISBN 978-3-319-19168-3.

6. Hurni, H. Degradation and conservation of the resources in the Ethiopian highlands. Mt. Res. Dev. 1988, 8, 123-130. [CrossRef]

7. FAO. Etiopian Highlands Reclamation Study; Ethiopia final report; Food and Agriculture Organization of the United Nations: Roma, Italy, 1986; Volume 2, Available online: http:/ / www.fao.org/3/ar864e/ar864e.pdf (accessed on 1 April 2021).

8. Wood, A. Natural resource management and rural development in Ethiopia. In Ethiopia: Rural Development Options; Pausewang, S., Cheru, F., Bruene, S., Chole, E., Eds.; Zed Books: London, UK, 2010; pp. 187-195.

9. Teketay, D. Deforestation, wood famine, and environmental degradation in Ethiopia's highland ecosystems: Urgent need for action. Northeast Afr. Stud. 2001, 8, 53-76. [CrossRef]

10. Yami, M.; Gebrehiwot, K.; Stein, M.; Mekuria, W. Impact of area enclosures on density and diversity of large wild mammals: The case of May Ba'ti, Douga Tembien District, Central Tigray, Ethiopia. East Afr. J. Sci. 2007, 1, 55-68. [CrossRef]

11. Woldu, G.; Solomon, N.; Hishe, H.; Gebrewahid, H.; Gebremedhin, M.A.; Birhane, E. Topographic variables to determine the diversity of woody species in the exclosure of Northern Ethiopia. Heliyon 2020, 6, e03121. [CrossRef]

12. Takahashi, K.; Homma, K.; Vetrova, V.P.; Florenzev, S.; Hara, T. Stand structure and regeneration in a Kamchatka mixed boreal forest. J. Veg. Sci. 2001, 12, 627-634. [CrossRef]

13. Hou, J.H.; Mi, X.C.; Liu, C.R.; Ma, K.P. Spatial patterns and associations in a Quercus-Betula forest in northern China. J. Veg. Sci. 2004, 15, 407-414. [CrossRef]

14. Teketay, D. Seed and regeneration ecology in dry Afromontane forests of Ethiopia: I. seed production-Population structures. Trop. Ecol. 2005, 46, 29-44.

15. White, J.C.; Coops, N.C.; Wulder, M.A.; Vastaranta, M.; Hilker, T.; Tompalski, P. Remote sensing technologies for enhancing forest inventories: A review. Can. J. Remote Sens. 2016, 42, 619-641. [CrossRef]

16. Lausch, A.; Erasmi, S.; King, D.J.; Magdon, P.; Heurich, M. Understanding forest health with remote sensing-Part II-a review of approaches and data models. Remote Sens. 2017, 9, 129. [CrossRef]

17. Mitchell, A.L.; Rosenqvist, A.; Mora, B. Current remote sensing approaches to monitoring forest degradation in support of countries measurement, reporting and verification (MRV) systems for REDD+. Carbon Balance Manag. 2017, 12. [CrossRef]

18. Popescu, S.C.; Wynne, R.H.; Nelson, R.F. Measuring individual tree crown diameter with lidar and assessing its influence on estimating forest volume and biomass. Can. J. Remote Sens. 2003, 29, 564-577. [CrossRef]

19. Côté, J.F.; Widlowski, J.L.; Fournier, R.A.; Verstraete, M.M. The structural and radiative consistency of three-dimensional tree reconstructions from terrestrial lidar. Remote Sens. Environ. 2009, 113, 1067-1081. [CrossRef]

20. Takahashi, T.; Awaya, Y.; Hirata, Y.; Furuya, N.; Sakai, T.; Sakai, A. Stand volume estimation by combining low laser-sampling density LiDAR data with QuickBird panchromatic imagery in closed-canopy Japanese cedar (Cryptomeria japonica) plantations. Int. J. Remote Sens. 2010, 31, 1281-1301. [CrossRef]

21. Itakura, K.; Hosoi, F. Estimation of leaf inclination angle in three-dimensional plant images obtained from lidar. Remote Sens. 2019, 11, 344. [CrossRef]

22. Guerra-Hernández, J.; González-Ferreiro, E.; Monleón, V.J.; Faias, S.P.; Tomé, M.; Díaz-Varela, R.A. Use of multi-temporal UAV-derived imagery for estimating individual tree growth in Pinus pinea stands. Forests 2017, 8, 300. [CrossRef]

23. Mlambo, R.; Woodhouse, I.H.; Gerard, F.; Anderson, K. Structure from Motion (SfM) photogrammetry with drone data: A low cost method for monitoring greenhouse gas emissions from forests in developing countries. Forests 2017, 8, 68. [CrossRef]

24. Bauwens, S.; Fayolle, A.; Gourlet-Fleury, S.; Ndjele, L.M.; Mengal, C.; Lejeune, P. Terrestrial photogrammetry: A non-destructive method for modelling irregularly shaped tropical tree trunks. Methods Ecol. Evol. 2017, 8, 460-471. [CrossRef]

25. Iglhaut, J.; Cabo, C.; Puliti, S.; Piermattei, L.; O'Connor, J.; Rosette, J. Structure from Motion photogrammetry in forestry: A review. Curr. For. Rep. 2019, 5, 155-168. [CrossRef]

26. Birhane, E.; Mengistu, T.; Seyoum, Y.; Hagazi, N.; Putzel, L.; Rannestad, M.M.; Kassa, H. Exclosures as forest and landscape restoration tools: Lessons from Tigray region, Ethiopia. Int. For. Rev. 2017, 19, 37-50. [CrossRef] 
27. Ubuy, M.H.; Eid, T.; Bollandsås, O.M.; Birhane, E. Aboveground biomass models for trees and shrubs of exclosures in the drylands of Tigray, northern Ethiopia. J. Arid Environ. 2018, 156, 9-18. [CrossRef]

28. Larjavaara, M.; Muller-Landau, H.C. Measuring tree height: A quantitative comparison of two common field methods in a moist tropical forest. Methods Ecol. Evol. 2013, 4, 793-801. [CrossRef]

29. Persson, A.; Holmgren, J.; Soderman, U. Detecting and measuring individual trees using an airborne laser scanner. Photogramm. Eng. Remote Sens. 2002, 68, 925-932.

30. Sibona, E.; Vitali, A.; Meloni, F.; Caffo, L.; Dotta, A.; Lingua, E.; Motta, R.; Garbarino, M. Direct measurement of tree height provides different results on the assessment of LiDAR accuracy. Forests 2017, 8, 7. [CrossRef]

31. Panagiotidis, D.; Abdollahnejad, A.; Surový, P.; Chiteculo, V. Determining tree height and crown diameter from high-resolution UAV imagery. Int. J. Remote Sens. 2017, 38, 2392-2410. [CrossRef]

32. Torres-Sánchez, J.; de Castro, A.I.; Peña, J.M.; Jiménez-Brenes, F.M.; Arquero, O.; Lovera, M.; López-Granados, F. Mapping the 3D structure of almond trees using UAV acquired photogrammetric point clouds and object-based image analysis. Biosyst. Eng. 2018, 176, 172-184. [CrossRef]

33. Ploton, P.; Mortier, F.; Barbier, N.; Cornu, G.; Réjou-Méchain, M.; Rossi, V.; Alonso, A.; Bastin, J.F.; Bayol, N.; Bénédet, F.; et al. A map of African humid tropical forest aboveground biomass derived from management inventories. Sci. Data 2020, 7, 1-13. [CrossRef] [PubMed]

34. Ganamé, M.; Bayen, P.; Ouédraogo, I.; Balima, L.H.; Thiombiano, A. Allometric models for improving aboveground biomass estimates in West African savanna ecosystems. Trees. For. People 2021, 4. [CrossRef]

35. Kikuzawa, K.; Lechowicz, M.J. Toward synthesis of relationships among leaf longevity, instantaneous photosynthetic rate, lifetime leaf carbon gain, and the gross primary production of forests. Am. Nat. 2006, 168, 373-383. [CrossRef]

36. Galia Selaya, N.; Anten, N.P.R. Leaves of pioneer and later-successional trees have similar lifetime carbon gain in tropical secondary forest. Ecology 2010, 91, 1102-1113. [CrossRef]

37. Miller, J.; Morgenroth, J.; Gomez, C. 3D modelling of individual trees using a handheld camera: Accuracy of height, diameter and volume estimates. Urban For. Urban Green. 2015, 14, 932-940. [CrossRef]

38. Mikita, T.; Janata, P.; Surovỳ, P. Forest stand inventory based on combined aerial and terrestrial close-range photogrammetry. Forests 2016, 7, 165. [CrossRef]

39. Piermattei, L.; Karel, W.; Wang, D.; Wieser, M.; Mokroš, M.; Surový, P.; Koreň, M.; Tomaštík, J.; Pfeifer, N.; Hollaus, M. Terrestrial structure from motion photogrammetry for deriving forest inventory data. Remote Sens. 2019, 11, 950. [CrossRef]

40. Marzulli, M.I.; Raumonen, P.; Greco, R.; Persia, M.; Tartarino, P. Estimating tree stem diameters and volume from smartphone photogrammetric point clouds. Forestry 2020, 93, 411-429. [CrossRef]

41. Weaver, S.A.; Ucar, Z.; Bettinger, P.; Merry, K.; Faw, K.; Cieszewski, C.J. Assessing the accuracy of tree diameter measurements collected at a distance. Croat. J. For. Eng. 2015, 36, 73-84.

42. Scher, C.L.; Griffoul, E.; Cannon, C.H. Drone-based photogrammetry for the construction of high-resolution models of individual trees. Trees Struct. Funct. 2019, 33, 1385-1397. [CrossRef]

43. Rose, J.; Paulus, S.; Kuhlmann, H. Accuracy analysis of a multi-view stereo approach for phenotyping of tomato plants at the organ level. Sensors (Switzerland) 2015, 15, 9651-9665. [CrossRef] [PubMed]

44. Ogawa, R.; Hirata, M.; Gebremedhin, B.G.; Uchida, S.; Sakai, T.; Koda, K.; Takenaka, K. Impact of differences in land management on natural vegetation in semi-dry areas: The case study of the Adi Zaboy watershed in the Kilite Awlaelo district, eastern Tigray region, Ethiopia. Environments 2019, 6, 2. [CrossRef]

45. Kassa, H.; Mezgebe, K.; Hagazi, N.; Cunningham, P.; Rinauldo, T.; Gebremeskel, G.; Darcha, G. Introduction and evaluation of Acacia saligna trees as backyard agroforestry system in eastern Tigray. In Proceedings of the International Conference of World Vision, Mekelle, Ethiopia, 7-8 March 2014; pp. 43-49.

46. Melese, S.M.; Ayele, B. Woody plant diversity, structure and regeneration in the Ambo State forest, South Gondar zone, Northwest Ethiopia. J. For. Res. 2017, 28, 133-144. [CrossRef]

47. Gelasso, M.; Li, J. Structure and regeneration status of woody species in the Munessa forest, Southern Ethiopia. J. For. Res. 2021, 32, 493-501. [CrossRef]

48. Aubert, S.; Boucher, F.; Lavergne, S.; Renaud, J.; Choler, P. 1914-2014: A revised worldwide catalogue of cushion plants 100 years after Hauri and Schröter. Alp. Bot. 2014, 124, 59-70. [CrossRef]

49. Bekele, T.; Berhan, G.; Ersado, M.; Taye, E. Regeneration status of moist Montane forests of Ethiopia: Part 11. Godere, Setema and Tiro-Boter becho forests. Walia 2003, 23, 19-32.

50. Brown, S.; Gillespie, A.J.R.; Lugo, A.E. Biomass estimation methods for tropical forests with applications to forest inventory data. For. Sci. 1989, 35, 881-902. [CrossRef] 